\title{
Research Paper \\ The Effect of One Circuit Training Session on the Serum Levels of Brain-Derived Neurotrophic Factor and Insulin-Like Growth Factor-1 in the Elderly
}

\author{
Vahid Valipour Dehnou ${ }^{1 *}$, Reza Motamedi²
}

1. Department of Sports Sciences, Faculty of Literature and Humanities, Lorestan University, Khorramabad, Iran.

2. Department of Physical Education, Faculty of Humanities, Borujerd Branch, Islamic Azad University, Borujerd, Iran.

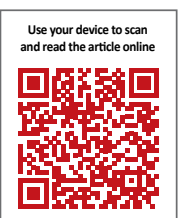

ditation Valipour Dehnou V, Motamedi R. [The Effect of One Circuit Training Session on the Serum Levels of Brain-Derived Neurotrophic Factor and Insulin-Like Growth Factor-1 in the Elderly (Persian)]. Iranian Journal of Ageing. 2019; 13(4):428-439. https://doi.org/10.32598/SIJA.13.4.428

https://doi.org/10.32598/SIJA.13.4.428

Keywords:

Sex, Elderly, Cognition, BDNF, IGF-1

\section{A B STRACT}

Received: 23 May 2018 Accepted: 10 Nov 2018 Available Online: 01 Jan 2019

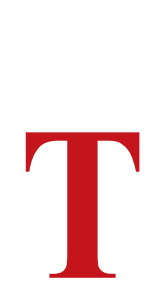

Extended Abstract

\section{Objectives}

he natural process of aging is associated with changes in the structure and function of the brain and related cogni- tive changes. Decreased recognition associated with increased age has been already reported. Some of these changes may be related to neurodegenerative diseases like Alzheimer disease and other types of dementia [1, 2]. Physical inactivity is an important risk factor for $\operatorname{cog}$ nitive decline [3-5] and Alzheimer disease [5, 6] in the elderly. On the contrary, moderate but regular exercise,

\section{* Corresponding Author:}

Vahid Valipour Dehnou, PhD.

Address: Department of Sports Sciences, Faculty of Literature and Humanities, Lorestan University, Khorramabad, Iran.

Tel: +98 (916) 6691874

E-mail: valipour.v@lu.ac.ir 
can have a protective effect even if initiated after midlife $[2,3,5]$. Physical activity can affect brain functions, including recognition, learning and memory [7]. Thus, this study examined the effect of 1 circuit training session on the serum levels of Brain-Derived Neurotrophic Factor (BDNF) and Insulin-like Growth Factor-1 (IGF-1) in elderly men and women.

\section{Methods and Materials}

This quasi-experimental study was conducted in 2016 . The study population consisted of elderly people living in the south of Khorramabad City, Iran. Five men (Mean \pm SD age $=64.40 \pm 6.69$ years, Mean \pm SD weight $=74.8 \pm 5.63$ $\mathrm{kg}$, Mean \pm SD height $=174.4 \pm 4.16 \mathrm{~cm}$ ), and 5 women $($ Mean \pm SD age $=64.5 \pm 60.55$ years, Mean \pm SD weight $=65 \pm 5.43 \mathrm{~kg}$, Mean $\pm \mathrm{SD}$ height $=167 \pm 5.48 \mathrm{~cm})$ participated voluntarily in this study. Inclusion criteria were aged $\geq 60$ years, complete physical and mental health and willingness to participate in the research.

The exclusion criteria were unwillingness to continue training and fatigue during the exercise. Almost one week before the training session, all the exercises were performed by the subjects at home with the presence of a coach. All subjects were acknowledged about the potential benefits and risks of the exercise. The research method was approved by the Ethics Committee of Lorestan University of Medical Sciences. For intervention, one session of circuit training was employed. In this regard, subjects performed body weight resistance exercises (resistance training) and fast walking (aerobic training). The training protocol is described in Table 1.

There was a 3-min rest between each movement. Five minutes before and 3 minutes after the training session, blood samples $(3 \mathrm{~mL})$ were obtained from the subjects. Blood samples were centrifuged for 5 minutes at 3500 rpm, then the serum was prepared. Serum levels of
BDNF and IGF-1 were measured by ELISA method and related kits (BDNF kits, sensitivity $=0.063 \mathrm{ng} / \mathrm{mL}$, detection range $=0.20-325 \mathrm{ng} / \mathrm{mL}$; IGF-1 kits, sensitivity $=1.95 \mathrm{ng} / \mathrm{mL}$, detection range $=7.80-500 \mathrm{ng} / \mathrm{mL}$ ), according to the manufacturer's instructions. The results of Shapiro-Wilk test suggested that the data were normally distributed. Therefore, Independent t-test and Analysis of Vovariance (ANCOVA) were used at the significance level of $\mathrm{P}<0.05$, for data analysis.

\section{Results}

In this quasi-experimental study, 10 elderlies (5 men and 5 women) living in the south of Khorramabad City participated. The pretest Mean \pm SD scores of BDNF levels in men and women were $5.53 \pm 0.45$ and $5.59 \pm 0.56 \mathrm{ng} / \mathrm{mL}$, respectively (total Mean $\pm \mathrm{SD}=5.56 \pm 0.48 \mathrm{ng} / \mathrm{mL}$ ). Their post-test Mean \pm SD levels were $6.79 \pm 1.36$ and $7.15 \pm 1.09 \mathrm{ng} /$ $\mathrm{mL}$, respectively (total Mean $\pm \mathrm{SD}=6.97 \pm 1.18 \mathrm{ng} / \mathrm{mL}$ ). The pretest Mean \pm SD scores of IGF-1 levels in men and women were $189.09 \pm 3.32$ and $179.02 \pm 20.80 \mathrm{ng} /$ $\mathrm{mL}$, respectively (total Mean $\pm \mathrm{SD}=184.06 \pm 15.01 \mathrm{ng} /$ $\mathrm{mL})$. In addition, their post-test Mean $\pm \mathrm{SD}$ score levels were $169.14 \pm 12.05$ and $156.88 \pm 18.34 \mathrm{ng} / \mathrm{mL}$, respectively (total Mean $\pm \mathrm{SD}=163.01 \pm 15.99 \mathrm{ng} / \mathrm{mL}$ ).

T-test results revealed that, BDNF level increased and IGF-1 level decreased in the samples $(\mathrm{P}<0.05)$. In men, the increase in BDNF level was not significant $(\mathrm{P}>0.05)$, while the same was significant in women $(\mathrm{P}<0.05)$. In respect of the IGF-1 levels, the obtained results indicated that its concentration decreased significantly in both elderly men and women $(\mathrm{P}<0.05)$. The results of Levene's test indicated the equality of variances. ANCOVA test reported that the difference between men and women in terms of BDNF level was not significant $(\mathrm{P}>0.05)$. The percentage of $\mathrm{BDNF}$ level changes in men $(22.78 \%)$ was lower than that in women

Table 1. Circuit training protocol

\begin{tabular}{cr}
\hline Movements & Methodology \\
\hline Push-up & Three rounds to exhaustion + jogging $(120 \mathrm{~m})$ between each round \\
\hline Bodyweight squat at $90^{\circ}$ & $3 \times 30$ repetitions + jogging $(120 \mathrm{~m})$ between each round \\
\hline Triceps dips & 15 repetitions + jogging $(120 \mathrm{~m})$ between each round $\times 3$ \\
\hline Plank & Three repetitions for 30 seconds + jogging $(120 \mathrm{~m})$ between each repetition \\
\hline Side plank & Three repetitions for 30 seconds + jogging $(120 \mathrm{~m})$ between each repetition \\
\hline
\end{tabular}


(27.91\%). The same was true for the changes in IGF-1 levels $(-10.55 \%$ in men and $-12.37 \%$ in women).

BDNF and IGF-1 are positive correlates of neurobiological adaptations that can be achieved through exercise and cognitive training $[5,8]$. BDNF concentrations change with increased age. Neuron reduction is associated with low levels of BDNF in the elderly. Some studies have reported higher levels of BDNF in women compared to men, while others have not stated such difference [9].

The results of this study also did not suggest a significant difference between elderly men and women. However, BDNF level increased significantly in elder women, while in elder men, its increase was not significant. IGF-1 level decreased after exercise which may be taken up by other tissues such as brain. This could be because exercising increases the brain uptake of IGF-1 which enhances the neuronal differentiation of ancestral cells and the expression of the BDNF gene in the hippocampus $[10,11]$. Animal model studies revealed that exercise, through increased IGF-1 uptake, prevents and protects the brain from damage [11].

\section{Conclusion}

In elderly women, one session of circuit training increased BDNF level and reduced IGF-1 level. In elderly men, IGF-1 level reduced; however, it did not significantly increase BDNF level. Also, there was no differences between base concentrations and their response to exercise in elderly men and women. Physical activity improves a number of physical diseases (e.g. cardiovascular disease, colorectal cancer, breast cancer, and obesity) and mental disorders (e.g. anxiety and depression). In addition, studies reported that aerobic training and resistance exercises are important lifestyle actions that affect cognitive functions [8, 12]. Therefore, according to the results of this study and other studies, it is suggested that elderly people perform aerobic exercises, muscle building exercises, flexibility training, and balance movements [13]. Such trainings must especially be combined with circular training for improving their mental and physical abilities. Moreover, with higher levels of fitness, the intensity of exercises should be higher, to create positive and significant effects.

\section{Ethical Considerations}

\section{Compliance with ethical guidelines}

This study has been approved by the Research Ethics Committee of Lorestan University of Medical Sciences.

Funding

This study has received financial support from Lorestan University of Medical Sciences

Authors contributions

Project Administration of this study was done by Vahid Valipour Dehnou.

\section{Conflict of interest}

The authors declared no conflict of interest. 


\title{
بررسى اثر يك جلسه تمرين دايرهاى بر سطوح BDNF و IGF-1 سرمى مردان و زنان سالمند
}

\author{
• وحيد ولىيور دمنو' •، رضا معتمدى' \\ ا - كروه علوم ورزشي، دانشكده ادبيات و علوم انسانى، دانشكاه لرستان، خرمآباده، ايران.

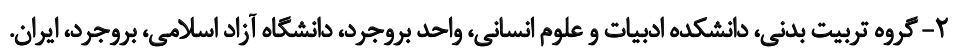

\begin{abstract}
حكبد

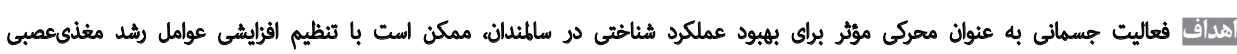

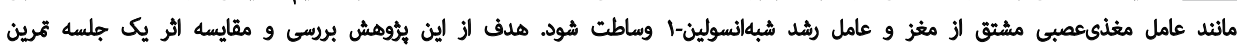

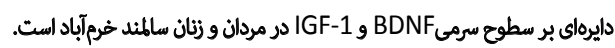

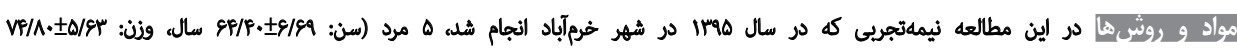

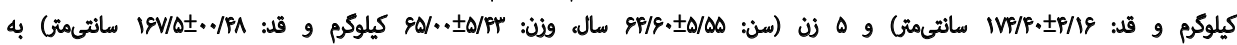

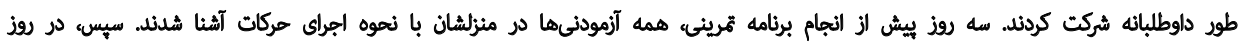

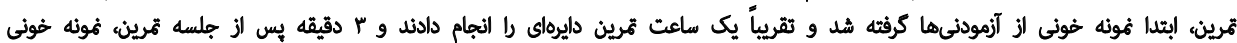

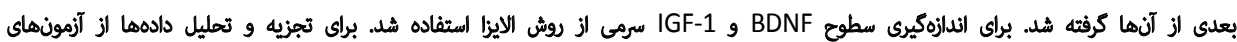

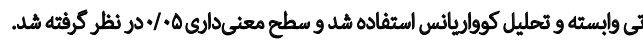

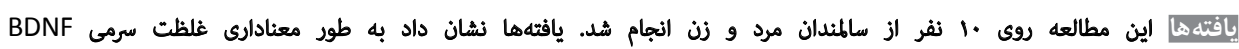

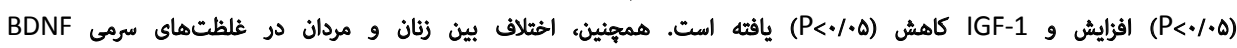

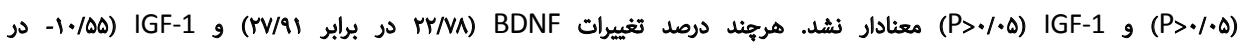
برابر

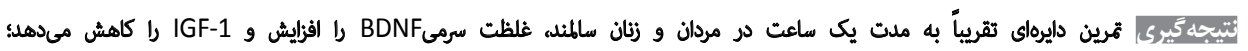

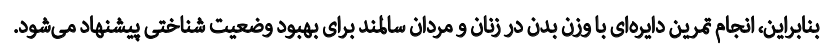

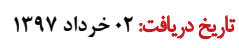

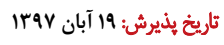

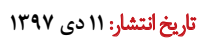

كليدوازوها:

جنس، سالمند، شناخت، BDNF ، IGF-1

نداشتن فعاليت جسمائى عاملى خطرناك و مهاي براى كاهش

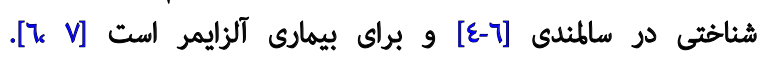

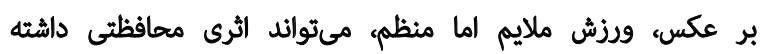

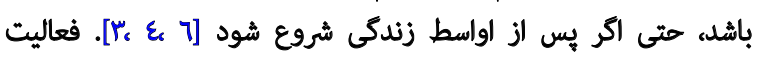

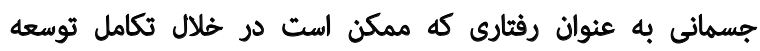

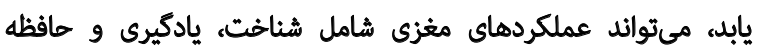
را تحت ثأثير قرار دهد [N]].

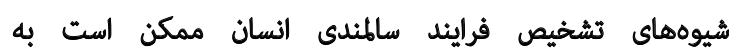

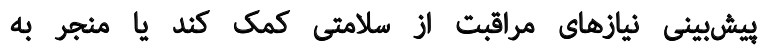

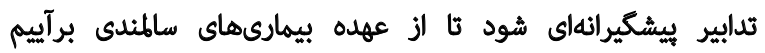

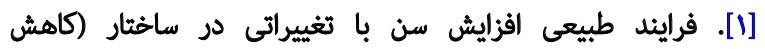
هجم مغز) و عملكرد مغز و تغييرات شناختى والبسته همراه است.

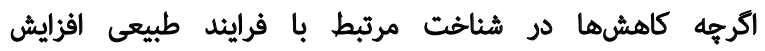
فعاليت جسمانى ممكن الست باعث نوعى بيشكيرى الوليه براى

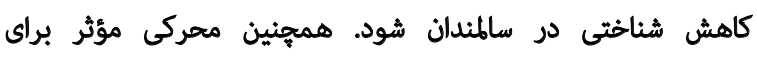

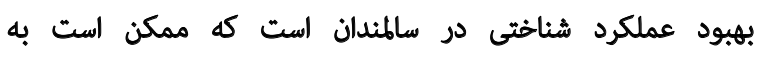

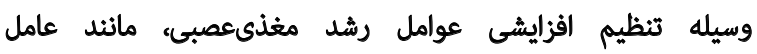

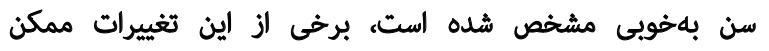

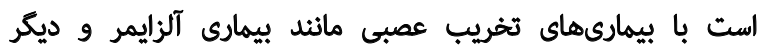

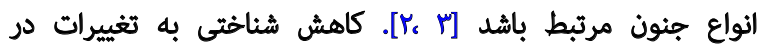

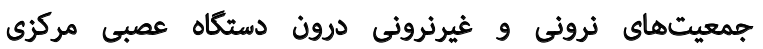

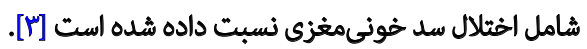

$$
\text { a. }
$$

: نويسنده مسئول:

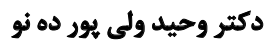

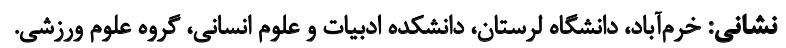
تلفن: valipour.v@lu.ac.ir بيت الكثرونيكي 
است و اختلالات عملكردى، فيزيولوزيكى و سوختوسازى مانئد

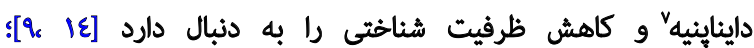

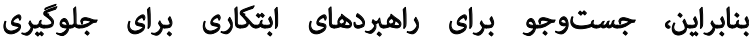

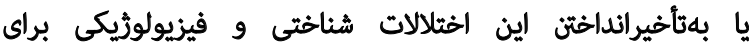

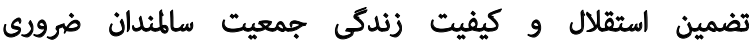

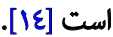

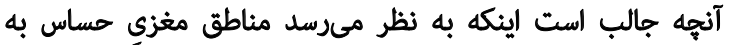

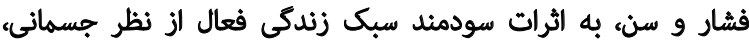

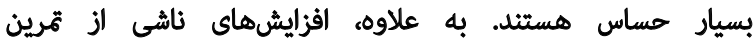

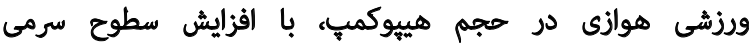
BDNF مرتبط است و آمادكى جسمانى بيشتر بيش ازئ از انجام

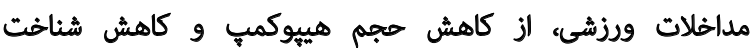

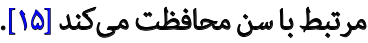

درنهايت، يروهشها قابليت محافظتى و اعادهكننده فعاليت

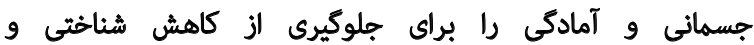

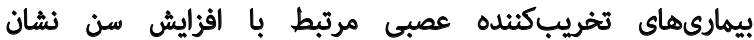

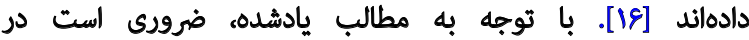

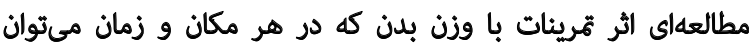

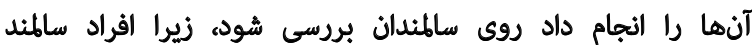

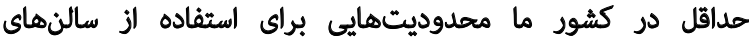

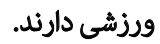

انجام تمرينات با وزنه براي افراد سالمند كه تجربه كافى ندارئده

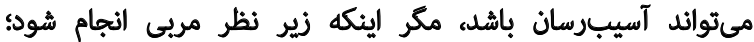

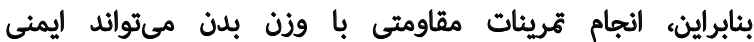

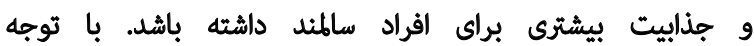

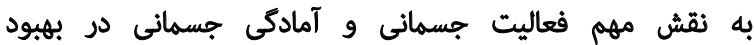

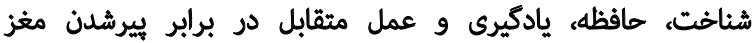

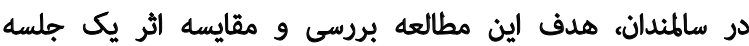

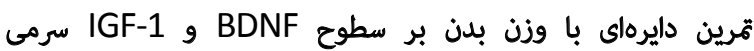

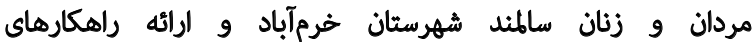

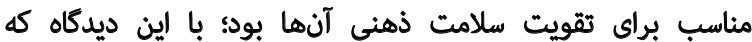
هنوز راجع به الثرات تمرين دايرهاي، يُروهشى انجام نشده است.

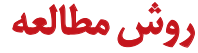

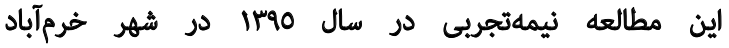

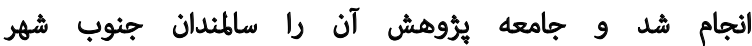

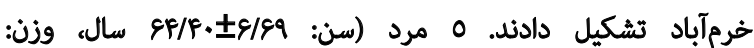
رو زن (سن:

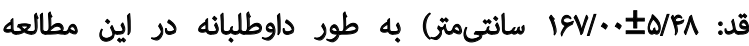

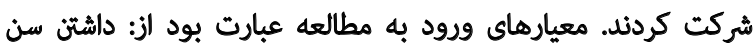

7. Dynapenia
مغذوعصبى مشتق از مغز' و عامل رشد شبهانسولين-ا' وساطت

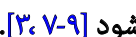

(kDa 27) BDNF كه فراوانترين عامل در خانواده عامل رشد

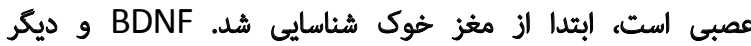

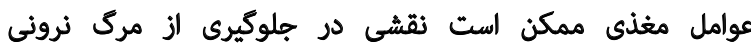

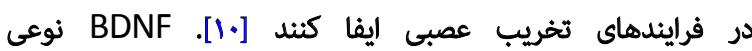

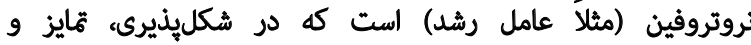

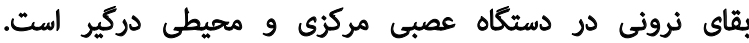

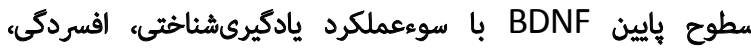

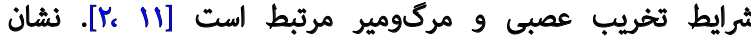

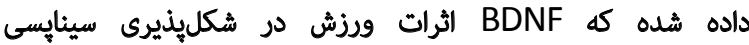

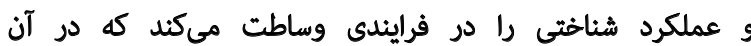

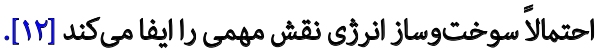

IGF-1 اثرات محافظتكنتده عصبىاى در مدلهاى آسيب به دستكاه عصبى مركزى دارد و تكثير سلول اجدادى و و نرونئهائ

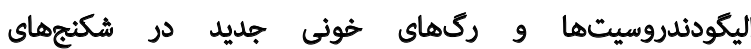

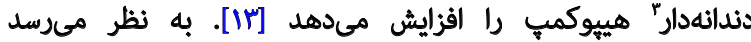

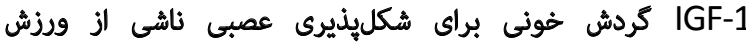

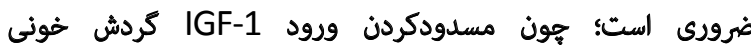
به درون مغز، به طور كامل اثرات عصبزايى و محافظتكنينده عصبى ورزش را از بين مىبرد [ه]].

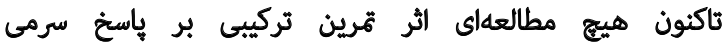
و و BDNF

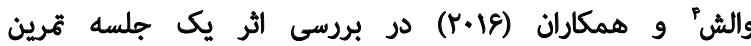

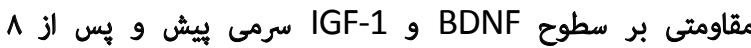

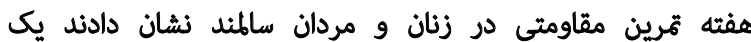

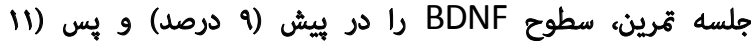

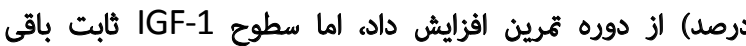

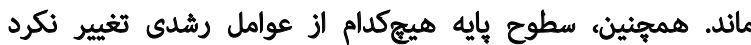

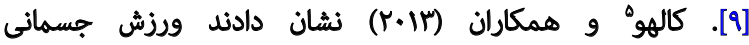
غلظتهاى محيطى BDNF در افراد سالمند را الفزايش ميدهان

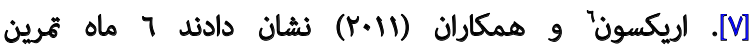

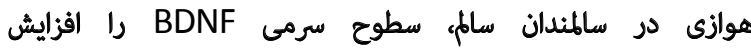

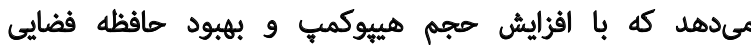

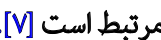

سالمندى فرايندى تخريبكننده است كه به كاهشهاى جشمكير در توده عضله، جإكالى استخوان و بافت مغز مرتبط

1. Brain Derived Neurotrophic Factor (BDNF)

2. Insulin-like growth factor-I (IGF-1)

3. Dentate gyrus

4. Walsh

5. Coelho

6. Erickson 
جدول ا. برئامه تمرينى

\begin{tabular}{|c|c|}
\hline روش أبرا & 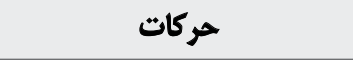 \\
\hline س دور تا واماندكى با + الا متر ييادمروى سريع بين هر دور & 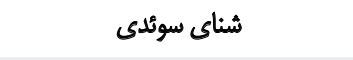 \\
\hline 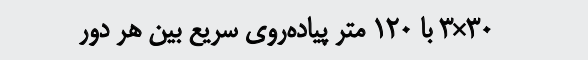 & اسكات با وزن بدن تا زاويه •9 درجه \\
\hline 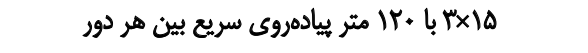 & ديب سه سر بازو \\
\hline 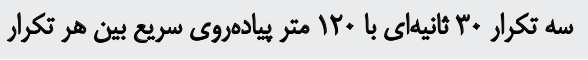 & 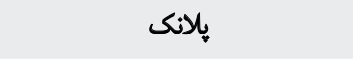 \\
\hline سه تكرار •ب ثانيهاي با ·ـا مثر ييادهروى سريع بين هر تكرار & يلانك جانبى (هر دو طرف بلن) \\
\hline
\end{tabular}

يلانك معكوس نيز طراحى شده بود كه آزمودنىها با وجود انكيزه

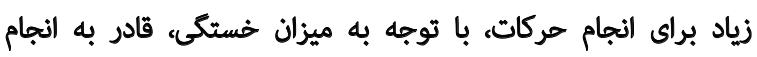

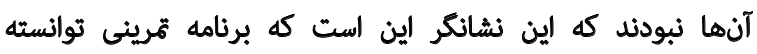
آزمودنىها را به حد كافى خسته كند.

ملتزمان انجام تمرين ثقريياً يك ساعت طول كشيد. در زمان

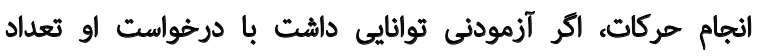

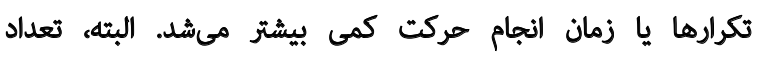

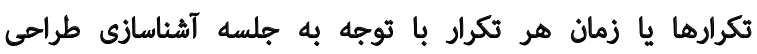

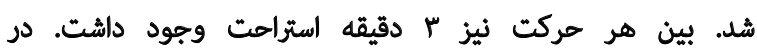

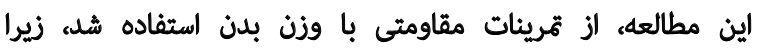

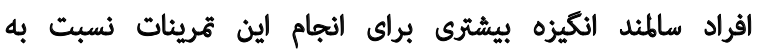
تمرينات با وزنههاي آزاد دارند.

\section{نمونه خونى}

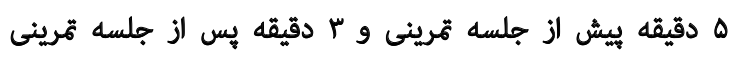

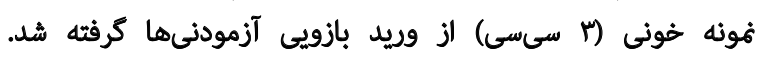

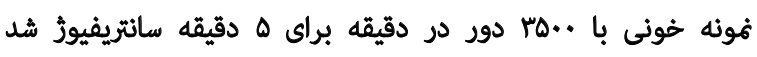

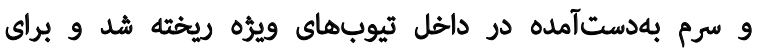

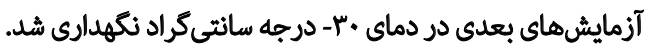

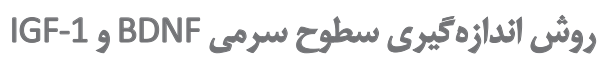

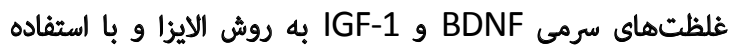

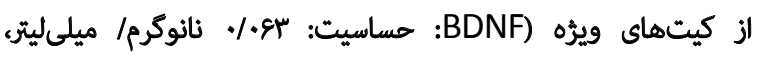

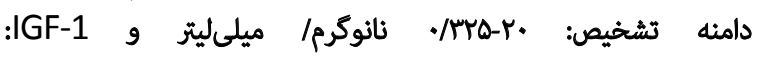

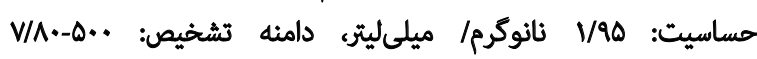

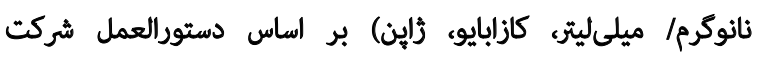
مربوطه اندازمكيرى شدند.

$$
\text { ووشّ هاي آمارى }
$$

نتايج آزمون شاييروويلك نشان داد دادهها توزيع طبيعى تونى

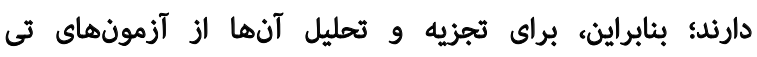

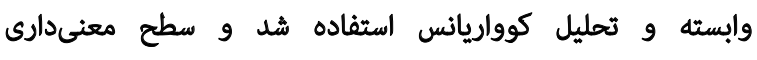

بالاى •7 ساله دالشتن سلامتى كامل جسمى و روانى و تمايل به

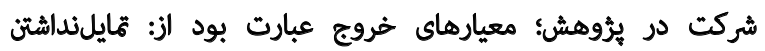
آزمودنى به الدامه تمرين و خستكى مفرط دريك معيارهاي خروج عين تمرين.

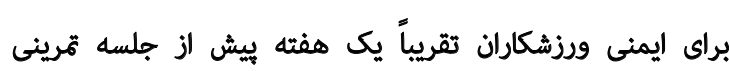

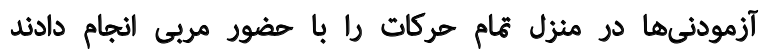

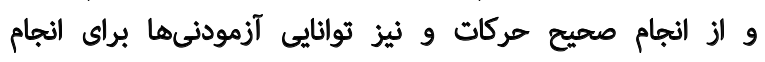

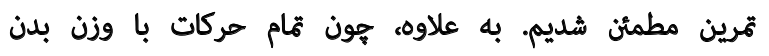

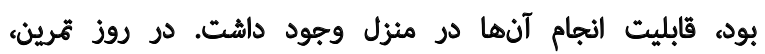

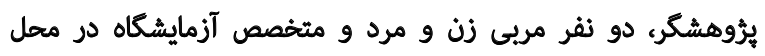

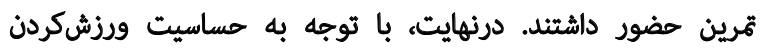

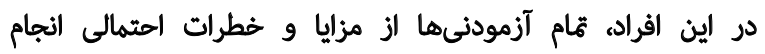

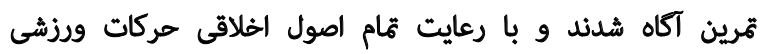
را النجام دادند.

\section{بونام تمبريني}

در اين مطالعه الز تمرين دايرهاي تركيبى استفاده شد، زيرا

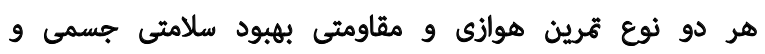

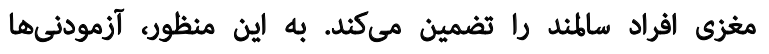

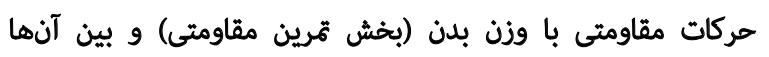

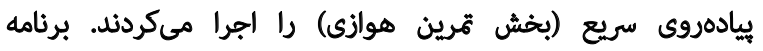

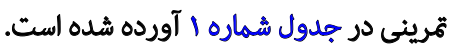

جند روز ييش از شروع جلسه تمرين، يك مربى مرد (براى

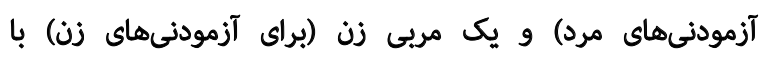

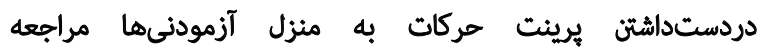

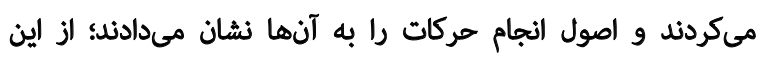

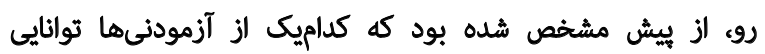

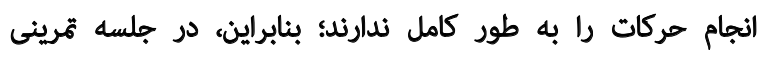

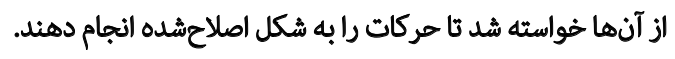
در حركات شئاى سوئدى و يلانكهاء آزمودنىهايى كه از ازئ

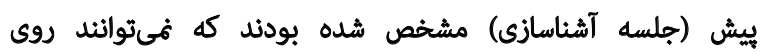

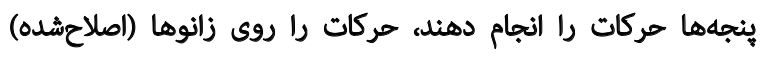

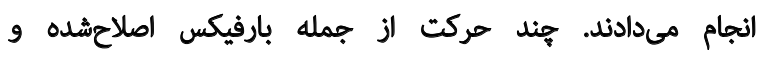


با وزن بدن شركت كردند. نتايج مهم اين مطالعه عبارتند از: ثمرين

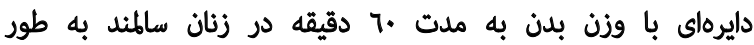

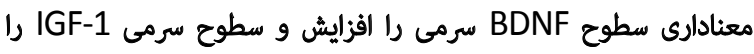

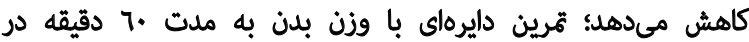

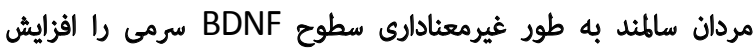

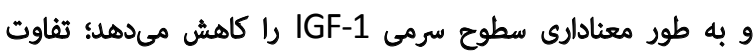

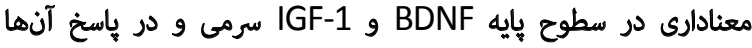
به ورزش بين زنان و مردان سالمند وجود ندائ سارد. هواهنك كنندهاي مثبت سازكارىهاى IGF-1 , BDNF

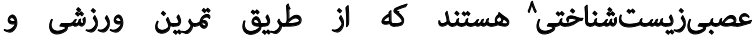

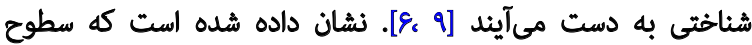
كردش خونى BDNF به وسيله عوامل بسيارى شامل جنس، سن، وزن بدن و وضعيت تغذيهاى تحت تأثير قرار مىكيرد.

غلظتهاى BDNF با افزايش سن تغيير مىيابد و مشخص شده كه

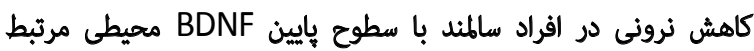

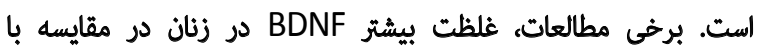

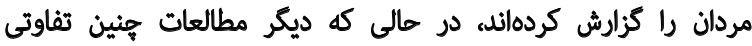

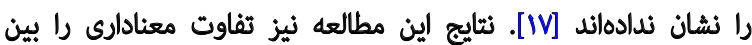

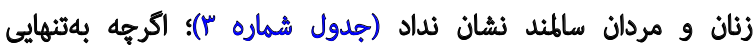

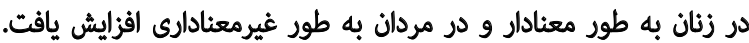

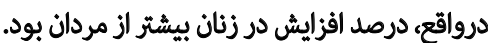

كزارش شده كه غلظت BDNF در سطوح سلولى و خارج

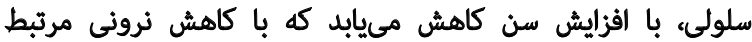

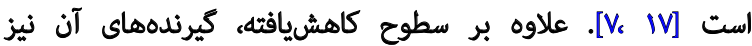

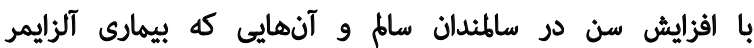

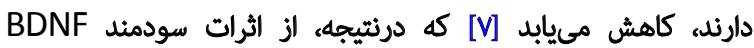

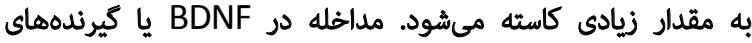

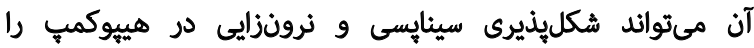

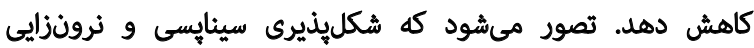

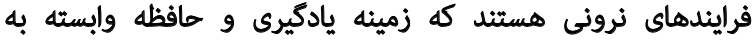

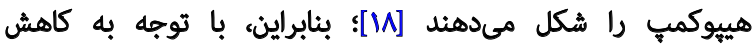

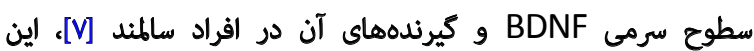

8. Neurobiological
P> P در نظر كرفته شد.

Latọl

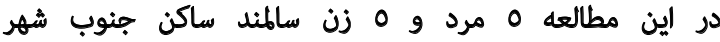

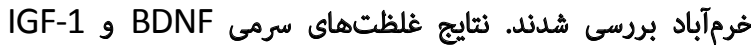

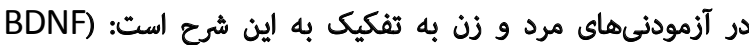

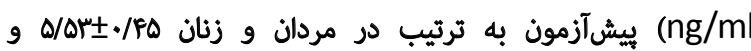

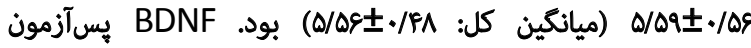

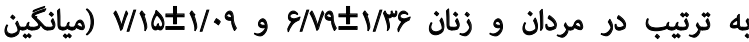

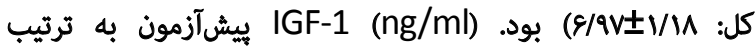
در مردان و زنان كل:

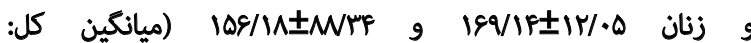

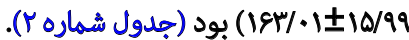

نتايج آزمون تى زوجى نشان مىدهد به طور معنادارى غلظت

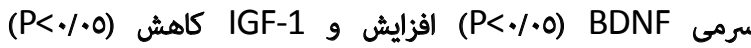

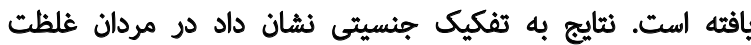

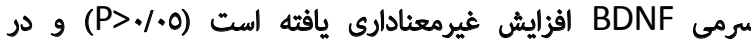

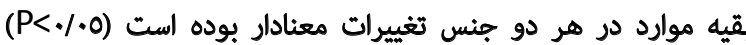

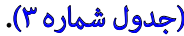

نتايج آزمون لون براى بروسى همكنى واريانسها و آناليز كوواريانس در جدول شماره ع آورده شده است. آين نتايج نشان

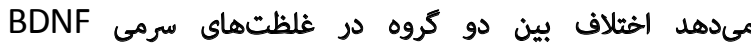

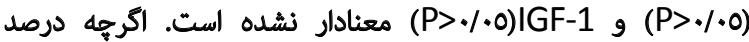

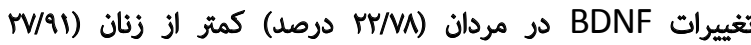

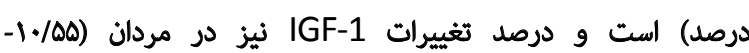
درصد) كمتر از زنان (Vآ/ آ درصد) است. بحث

اين مطالعه با هدف بررسى و مقايسه اثر يك جلسه تمرين

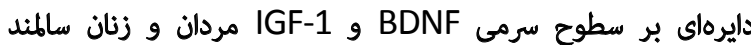

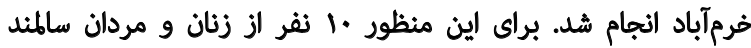

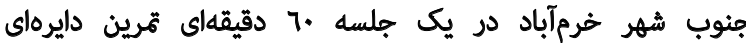

جدول r. غلظتهاي سرمى BDNF , وFF-1 (ميانكين土انحراف معيار)

\begin{tabular}{|c|c|c|c|c|}
\hline \multicolumn{2}{|c|}{ IGF-1 (ng/ml) } & \multicolumn{2}{|c|}{ BDNF (ng/ml) } & \\
\hline بسآزمون & بيش آزمون & بسآزمون & بيش آزمون & \\
\hline$\left|\varepsilon q / / F_{ \pm}\right| r /+\Delta$ & $119 / \cdot q_{ \pm} r / r r$ & $s / N q_{ \pm} / /{ }^{\prime} s$ & $\Delta / \Delta \mu_{ \pm} \cdot / / \phi$ & مرد \\
\hline$I \Delta S / M_{ \pm} \mid N / F$ & $\mid r q / r_{ \pm} r \cdot / \Lambda \cdot$ & $\left.v / / \Delta_{ \pm}\right) / \cdot q$ & $\Delta / \Delta q_{ \pm} \cdot / \Delta F$ & زن \\
\hline $19 \% / 1 . \pm 10 / 99$ & $|A F| \cdot \varepsilon_{ \pm} \mid \Delta / \cdot 1$ & $s / a q_{ \pm} \mid / / \mu$ & $\Delta / \Delta \varepsilon_{ \pm} \cdot / \not \Lambda$ & كل \\
\hline
\end{tabular}


جدول ب. نتايج آزمون تى زوجى

\begin{tabular}{|c|c|c|}
\hline Sig. & $\mathbf{t}$ & متغيرها \\
\hline $.1++1$ & $-F / q+1$ & BDNF \\
\hline $.1 .+1$ & D/Far & IGF-1 \\
\hline
\end{tabular}

2

جدول P. نتايج آزمونهاي لون و كوواريانس

\begin{tabular}{|c|c|c|c|c|}
\hline \multicolumn{2}{|c|}{ آزمون كوواريانس } & \multicolumn{2}{|c|}{ آزمون لون } & \multirow{2}{*}{ متغيرها } \\
\hline $\mathbf{P}$ & $\mathbf{F}$ & $\mathbf{P}$ & $\mathbf{F}$ & \\
\hline $.18 \pi$ &.$/ 190$ &.$/ 7 v a$ & . INE & BDNF \\
\hline . /DPT &.$/ 411$ & $\cdot / \Delta V T$ & ./MPA & IGF-1 \\
\hline
\end{tabular}

\section{2}

دايرهاي را توجيه كند، زيرا با توجه به سبك زندكى افراد اين

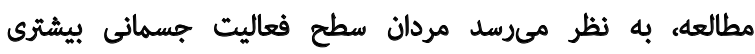

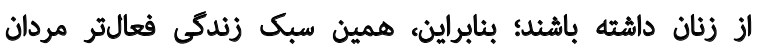

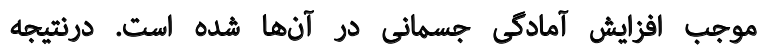

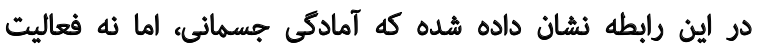

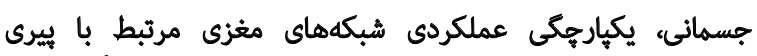

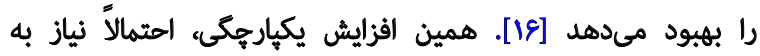

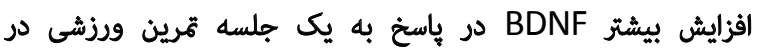

افر الد آمادهتر راكاهش ميثد مهد.

فرايند سالمندى طبيعى به كاهش عملكرد جسمانى و سطوح

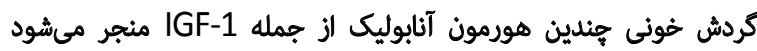

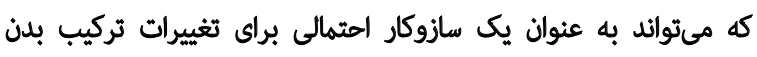

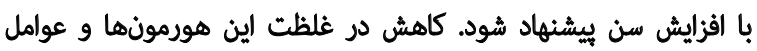

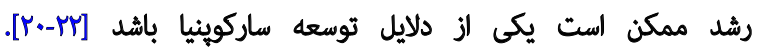

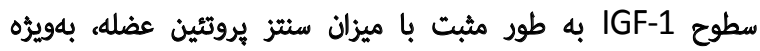

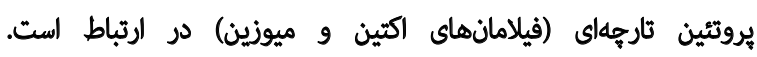

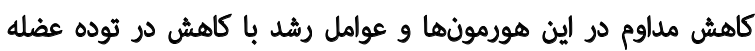

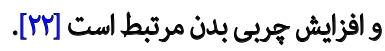

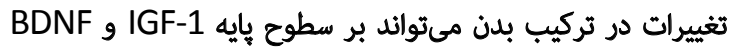

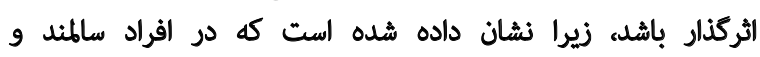

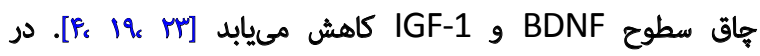

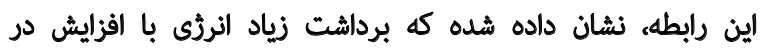

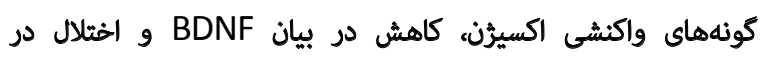

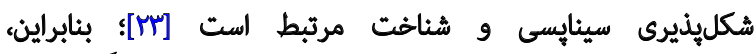
يكى از دلايل كاهش عوامل رشد در الفراد سالكند احتمالاً تغييرات در تركيب بدن و كاهش سطح فعاليت جسمانى آنهاست.

IGF-1 به عنوان وساطتكننده اثرات ورزش عمل مىكند و
اثرات مخرب سالمندى بر حافظه و يادكيرى را مىتوان تا حدودى بهوسيله تمرين ورزشي الز بين برد.

بيشتر مطالعات انسانى افزايش كذرايى (وابسئه به شدت دات

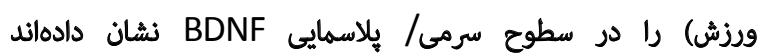

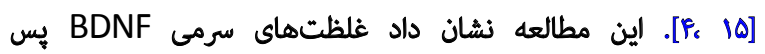

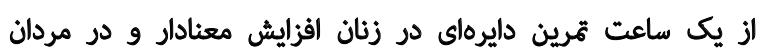

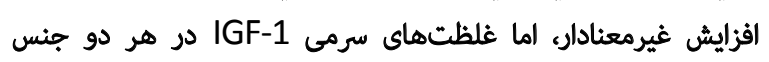

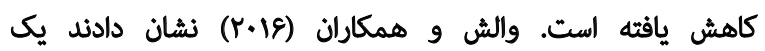

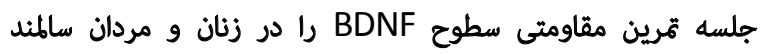

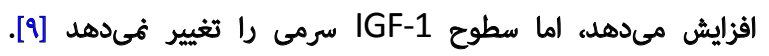

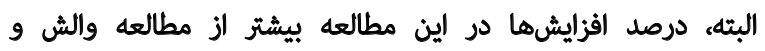

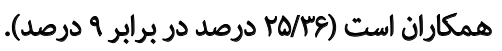
در مطالعهاي ديكر نشان داده شده كه يك جلسه ثمرين هوازى

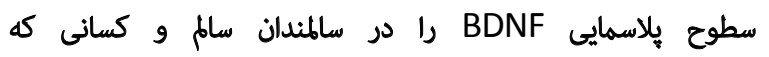

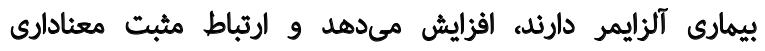

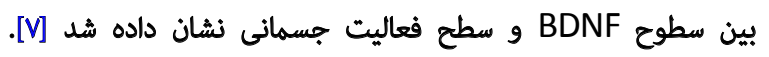

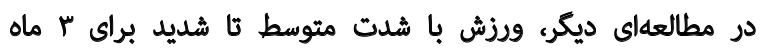

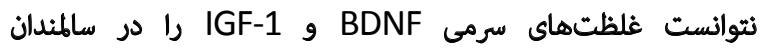

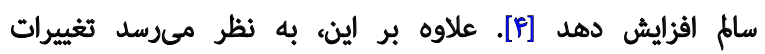

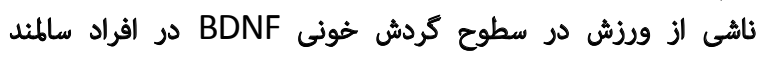
ممكن است بر طبق نوع ورزش جسمانى (ورزش هورازى ديا يا تمرين

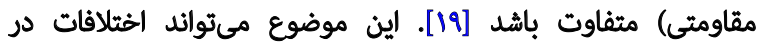

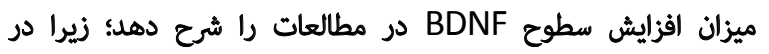

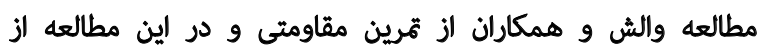

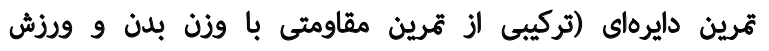
هوالزي) استفاده شده استيت. سطح آمادكى جسمانى بيشبين زنان و مردان سالهند اين

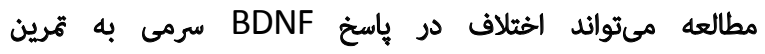


1 براى ركزايى ناشى از ورزش در مغز ضرورى است. IGF-1

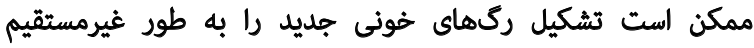

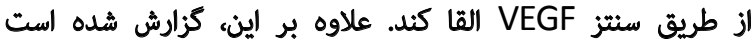

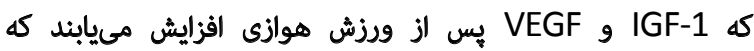

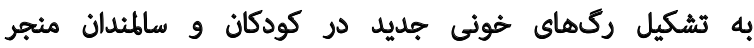

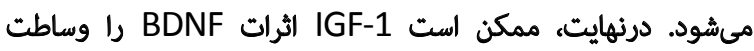

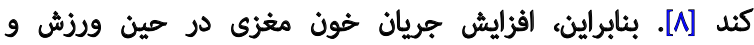

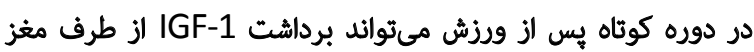

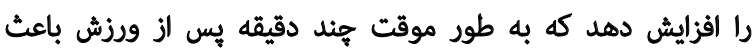

$$
\text { كاهش سطوح سرمى آن مىشود. }
$$

سيستم ركى مغز در سرثاسر عمر بسيار شكليذير است.

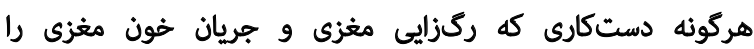

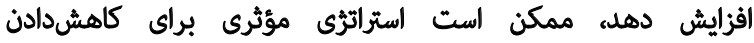

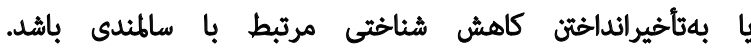

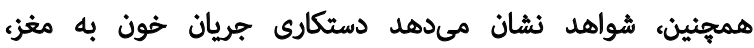

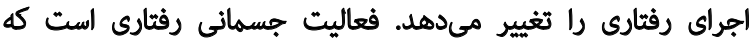

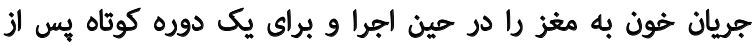

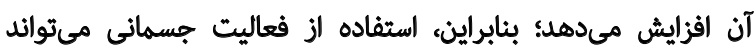

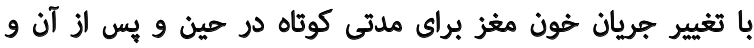

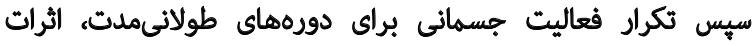
مثبتى بر بهبود اجراي شناختى داشته باشد [م]].

\section{نتيجه كيرى نهايى}

تمرين دايرهاي (تمرين مقاومتى با وزن بدن و بيادمروى سريع)

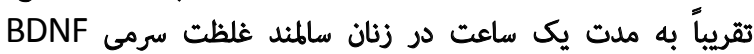

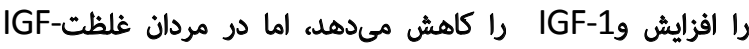

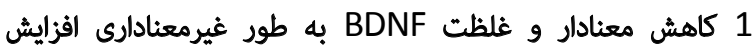

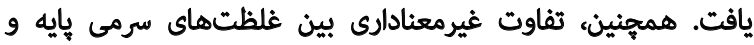

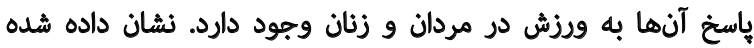

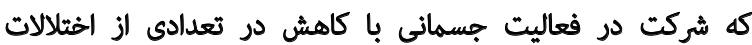

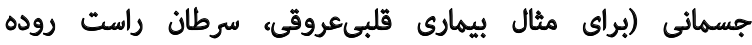

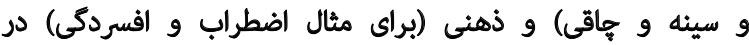
سرتاسر طول عمر بالغان مرتبط است.

يُؤششها نشان دادهاند كه ورزش هوازى و مقاومثى از عوامل

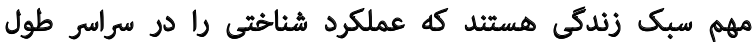

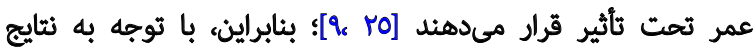

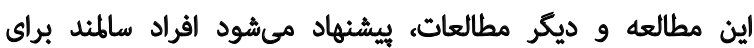

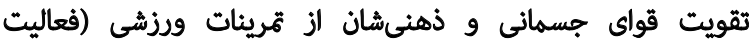

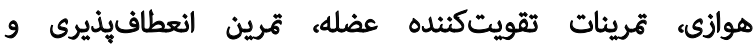

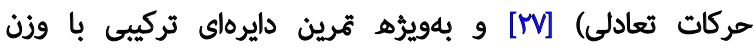

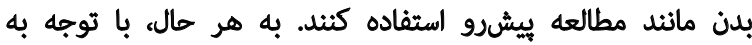

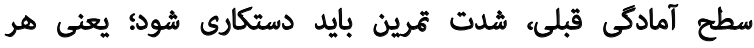

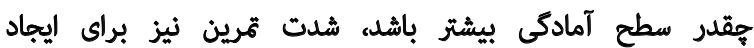

عامل رشدى است كه در نقش يك عامل بقاى نيرومند براى نرونها

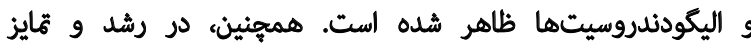

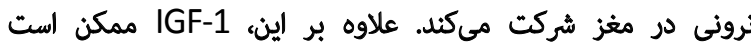

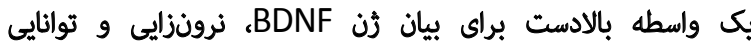

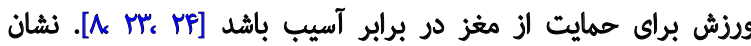

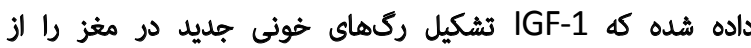

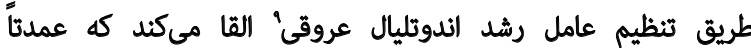

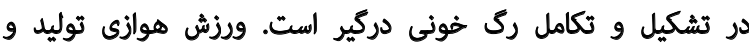

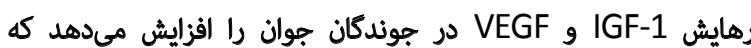

به تشكيل ركهاى خونى جديد منجر مىشود [Yr]

در اين مطالعه سطوح سرمى IGF-1 يس از ورزش كاهش

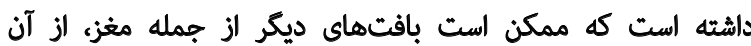

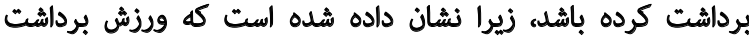

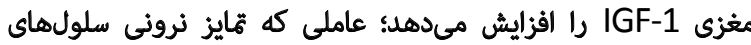

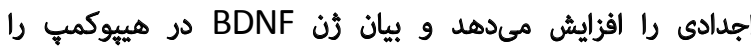

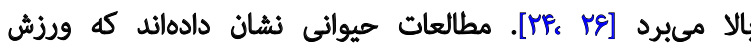

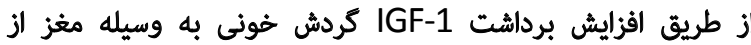

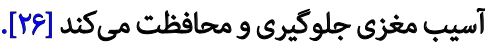

كاهش در غلظتهاي سرمى IGF-1 ممكن است به دليل

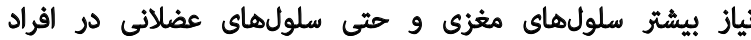

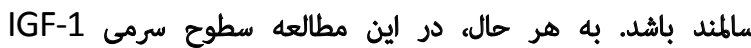

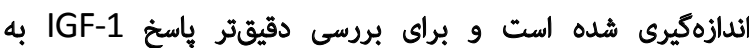

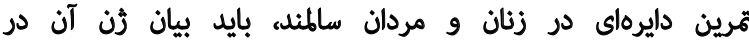

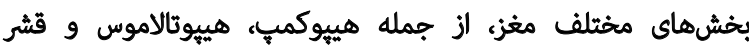

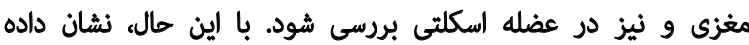

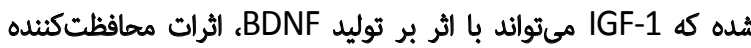

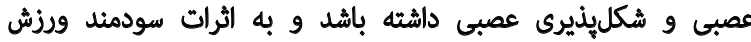

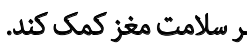

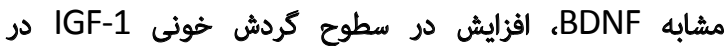

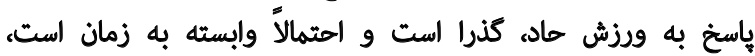

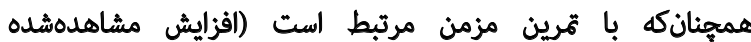

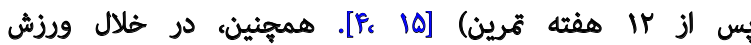

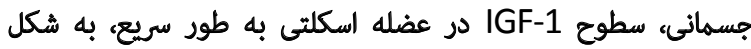

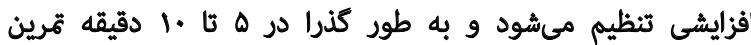

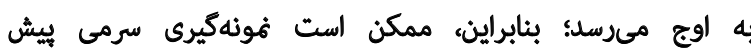

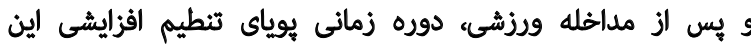

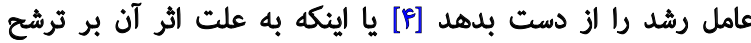

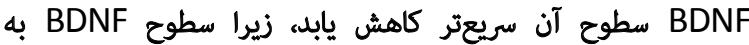
طور معنادارى در اين مطالعه افزايش يافته است.

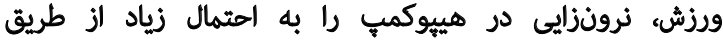

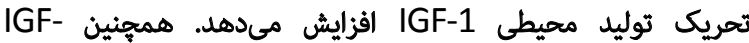

9. Vascular Endothelial Growth Factor (VEGF) 
اثرات مثبت و معنادار بايد بيشُتر باشد.

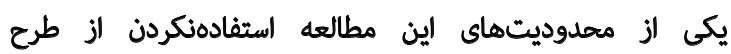

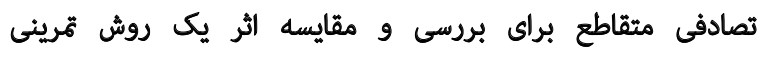

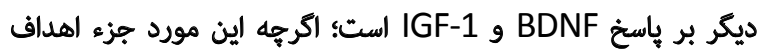

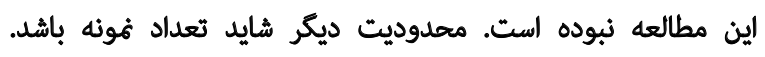

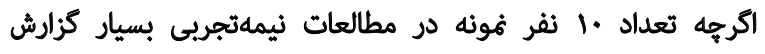

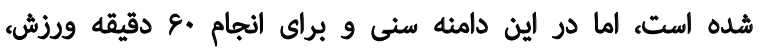
يافتئ مُونه بسيار سخت است است.

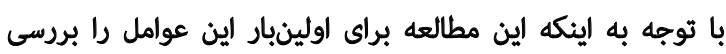

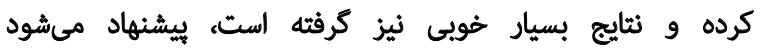

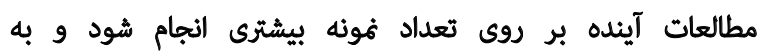

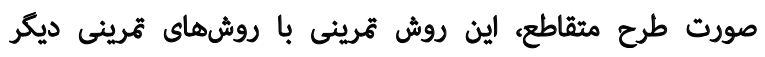

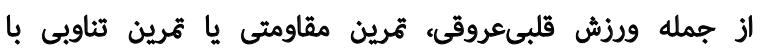

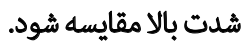
مالامظات الغلاقي بيروى أز الصول اخلاق بُوههش كميته الخلاق دانشكاه لرسئان اين بُروهش را تأييد كرده است.

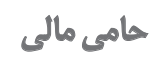

اين هيزوهش الز طرح دروندانشكاهى دانشكاه لرستان كرفته

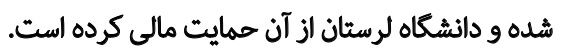

$$
\text { مشاركت نويسئد مان }
$$

مثام نويسندكان مر آمادهازى اين مقاله مشاركت داشثتهاند.

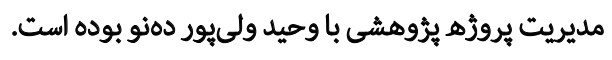

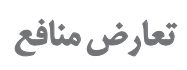

بنا بر اظهار نويسندكان اين مقاله تعارض منافع ندارد. 


\section{References}

[1] Sood S, Gallagher IJ, Lunnon K, Rullman E, Keohane A, Crossland $\mathrm{H}$, et al. A novel multi-tissue RNA diagnostic of healthy ageing relates to cognitive health status. Genome Biology. 2015; 16(185):1-17.

[2] Kirk Sanchez NJ, McGough EL. Physical exercise and cognitive performance in the elderly: Current perspectives. Clinical Interventions in Aging. 2014; 9:51-62. [DOI:10.2147/CIA.S39506] [PMID] [PMCID]

[3] Proia P, Di Liegro CM, Schiera G, Fricano A, Di Liegro I. Lactate as a metabolite and a regulator in the central nervous system. International Journal of Molecular Sciences. 2016; 17(1450):1-20. [DOI:10.3390/ijms17091450]

[4] Duzel E, van Praag H, Sendtner M. Can physical exercise in old age improve memory and hippocampal function? Brain. 2016; 139(3):662-73. [DOI:10.1093/brain/awv407]

[5] Seene T, Kaasik P. Age-associated changes in skeletal muscle regeneration: Effect of exercise. Advances in Aging Research. 2015; 4:230-41

[6] Boecker H, Hillman CH, Scheef L, Strüder HK. Functional neuroimaging in exercise and sport sciences. Berlin: Springer; 2012.

[7] Coelhoa FGM, Vitala TM, Steina AM, Arantesa FJ, Ruedac AV, Camarinic $R$, et al. Acute aerobic exercise increases brain-derived neurotrophic factor levels in elderly with Alzheimer's disease. Journal of Alzheimer's Disease. 2014; 39(2):401-8. [DOI:10.3233/ JAD-131073]

[8] Lista I, Sorrentino G. Biological mechanisms of physical activity in preventing cognitive decline. Cellular and Molecular Neurobiology. 2010; 30(4):493-503. [DOI:10.1007/ s10571-009-9488-x] [PMID]

[9] Walsh JJ, Scribbans TD, Bentley RF, Kellawan JM, Gurd B, Tschakovsky ME. Neurotrophic growth factor responses to lower body resistance training in older adults. Applied Physiology, Nutrition, and Metabolism. 2016; 41(3):315-23.

[10] Zoladz JA, Pilc A, Majerczak J, Grandys M, Zapart bukowska J, Duda K. Endurance training increases plasma brain-derived neurotrophic factor concentration in young healthy men. Journal of Physiology and Pharmacology. 2008; 59(7):119-32. [PMID]

[11] Swift DL, Johannsen NM, Myers VH, Earnest CP, Smits JAJ, Blair SN, et al. The effect of exercise training modality on serum brain derived neurotrophic factor levels in individuals with type 2 diabetes. PLOS One. 2012; 7(8):1-7. [DOI:10.1371/journal. pone.0042785]

[12] Gomez Pinilla F, Vaynman S, Ying Z. Brain-derived neurotrophic factor functions as a metabotrophin to mediate the effects of exercise on cognition. European Journal of Neuroscience. 2008; 28(11):2278-87. [DOI:10.1111/j.14609568.2008.06524.x] [PMID] [PMCID]

[13] Åberg ND, Brywe KG, Isgaard J. Aspects of growth hormone and insulin-like growth factor-I related to neuroprotection, regeneration, and functional plasticity in the adult brain. The Scientific World Journal. 2006; 6:53-80. [DOI:10.1100/tsw.2006.22]

[14] Smolarek AC, Ferreira LHB, Mascarenhas LPG, McAnulty SR, Varela KD, Dangui MC, et al. The effects of strength training on cognitive performance in elderly women. Clinical Interventions in Aging. 2016; 11:749-54. [DOI:10.2147/CIA.S102126]
[15] Silverman MN, Deuster PA. Biological mechanisms underlying the role of physical fitness in health and resilience. Interface Focus. 2014; 4(5):1-12. [DOI: 10.1098/rsfs.2014.0040] [PMID] [PMCID]

[16] Voss MW, Weng TB, Burzynska AZ, Wong CN, Cooke GE, Clark R, et al. Fitness, but not physical activity, is related to functional integrity of brain networks associated with aging. NeuroImage. 2016; 131:113-25. [DOI:10.1016/j.neuroimage.2015.10.044] [PMID] [PMCID]

[17] Forti LN, Roie EV, Njemini R, Coudyzer W, Beyer I, Delecluse $\mathrm{C}$, et al. Dose-and gender-specific effects of resistance training on circulating levels of Brain Derived Neurotrophic Factor (BDNF) in community-dwelling older adults. Experimental Gerontology. 2015; 70:144-9. [DOI:10.1016/j.exger.2015.08.004] [PMID]

[18] Forti LN, Njemini R, Beyer I, Eelbode E, Meeusen R, Mets T, et al. Strength training reduces circulating interleukin- 6 but not brain-derived neurotrophic factor in community-dwelling elderly individuals. Age (Dordr). 2014; 36(5):9704. [DOI:10.1007/ s11357-014-9704-6] [PMID] [PMCID]

[19] Kanoski SE, Davidson TL. Western Diet Consumption and Cognitive Impairment: Links to Hippocampal Dysfunction and Obesity. Physiology \& Behavior. 2011; 103(1):59-68. [DOI: 10.1016/j.physbeh.2010.12.003] [PMID] [PMCID]

[20] Proctor DN, Balagopal P, Nair KS. Age-related Sarcopenia in humans is associated with reduced synthetic rates of specific muscle proteins. Journal of Nutrition. 1998; 128(Suppl.2):351-55. [DOI:10.1093/jn/128.2.351S] [PMID]

[21] Nikolic M, Bajek S, Bobinac D, Vranic TS, Jerkovic R. Aging of human skeletal muscles. Collegium Antropologicum. 2005; 29(1):67-70. [PMID]

[22] Arnarson A, Gudny Geirsdottir O, Ramel A, Jonsson PV, Thorsdottir I. Insulin-like growth factor-1 and resistance exercise in community dwelling old adults. The Journal of Nutrition, Health and Aging. 2015; 19(8):856-60.

[23] Farooqui T, Farooqui AA. Diet and exercise in cognitive function and neurological diseases. Hoboken: Wiley-Blackwell; 2015.

[24] Cotman CW, Berchtold NC. Exercise: A behavioral intervention to enhance brain health and plasticity. Trends in Neurosciences. 2002; 25(6):295-301. [PMID]

[25] Hillman CH, Erickson KI, Kramer AF. Be smart, exercise your heart: exercise effects on brain and cognition. Nature Reviews, Neuroscience. 2008; 9(1):58-65. [DOI:10.1038/nrn2298] [PMID]

[26] Maass A, Düzel S, Brigadski T, Goerke M, Becke A, Sobieray $\mathrm{U}$, et al. Relationships of peripheral IGF-1, VEGF and BDNF levels to exercise-related changes in memory, hippocampal perfusion and volumes in older adults. NeuroImage. 2016; 131:142-54 [DOI:10.1016/j.neuroimage.2015.10.084] [PMID]

[27] Lautenschlager NT, Cox K, Cyarto EV. The influence of exercise on brain aging and dementia. Biochimica et Biophysica Acta. 2012; 1822(3):474-81. [DOI:10.1016/j.bbadis.2011.07.010] [PMID] 
This Page Intentionally Left Blank 